\title{
(and
}

RESEARCH AND EDUCATION

\section{A photoelastic and strain gauge comparison of two attachments for obturator prostheses}

\author{
Marcelo Coelho Goiato, MS, PhD, ${ }^{a}$ Henrique Rinaldi Matheus, ${ }^{b}$ Rodrigo Antonio de Medeiros, DDS, MS, \\ Daniela Micheline dos Santos, MS, PhD, ${ }^{d}$ Sandro Basso Bitencourt, DDS, ${ }^{e}$ and \\ Aldiéris Alves Pesqueira, MS, $\mathrm{PhD}^{\mathrm{f}}$
}

A maxillectomy is performed for different reasons, including congenital malformation, trauma, and benign or malignant neoplastic growth. ${ }^{1-3}$ It can promote oral-nasal-sinus communication, ${ }^{2,3}$ allowing passage of air, fluid, and food between these cavities. This can affect speech, mastication, and swallowing and decrease quality of life. ${ }^{2,4}$

The rehabilitation of patients after a maxillectomy is important and varies according to the age and medical history of the patient. An obturator prosthesis is frequently chosen for rehabilitation because reconstructive plastic surgeries are invasive and complicated.

The purpose of this prosthesis is to seal the oral-nasalsinus communication, recovering mastication, swallowing, and speech. ${ }^{4,5}$

After a maxillectomy, patients experience a substantial loss, not only of soft tissue but also of bone, ${ }^{3}$ resulting in instability of conventional obturator dentures during

\begin{abstract}
Statement of problem. The rehabilitation of patients after a maxillectomy involves the use of an obturator to seal oral-nasal-sinus communication and to facilitate mastication, swallowing, and speech.

Purpose. The purpose of this in vitro study was to evaluate different attachment systems used for implant-retained obturators at dissipation loads and under shear forces.

Material and methods. Photoelastic models were fabricated with 3 external hexagon implants at the incisor, canine, and first molar regions. Subsequently, overdentures were made, and metal hooks were placed at the incisor and first molar regions to displace the prostheses in the vertical, anterior, and posterior directions, with a constant speed of $50 \mathrm{~mm} / \mathrm{min}$. A photoelastic model with an O-ring or bar-clip system was placed in a circular polariscope, and tested with a universal testing machine. The images were recorded and high-intensity fringes were counted using software. For strain gauge analysis, each strain gauge was placed horizontally at the mesial and distal sides of the implants. The registered strains were submitted to 2-way ANOVA $(\alpha=.05)$.
\end{abstract}

Results. The O-ring showed the lowest number of high-intensity fringes in photoelastic imaging, while the strain gauge analysis showed the lowest stress values in the bar-clip group $(P=.007)$.

Conclusions. The stress around titanium implant necks was more damaging to surrounding bone, while the bar-clip attachment system had a better biomechanical performance. The barclip presented the lowest strain values around the dental implants and few high-intensity fringes. (J Prosthet Dent 2017;117:685-689)

daily events such as mastication. ${ }^{6}$ Implants and attachment systems have aided rehabilitation in these situations. $1,2,7,8$ Some studies have verified that spherical attachments transfer less tensile stress to implants than bar-clips ${ }^{9-11}$; other studies, however, have reported the contrary. ${ }^{12,13}$

\footnotetext{
Supported by São Paulo Research Foundation (FAPESP) (grant 2014/04919-1).

aProfessor, Aracatuba Dental School, São Paulo State University (UNESP), São Paulo, Brazil.

bGraduate student, Aracatuba Dental School, Sao Paulo State University (UNESP), São Paulo, Brazil.

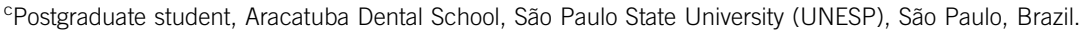

${ }^{d}$ Professor, Aracatuba Dental School, São Paulo State University (UNESP), São Paulo, Brazil.

ePostgraduate student, Aracatuba Dental School, São Paulo State University (UNESP), São Paulo, Brazil.

fProfessor, Aracatuba Dental School, São Paulo State University (UNESP), São Paulo, Brazil.
} 


\section{Clinical Implications}

The main challenge associated with maxillofacial obturator dentures is a lack of stability and retention due to the size and configuration of the defect. In these situations, implant-supported overdentures are an effective option. However, knowing and improving the geometric arrangement of the assembly (attachment/implant/ bone) during daily events such as prosthesis removal is essential. This is necessary to prevent marginal bone loss and to guarantee the longevity of implant-supported prosthetic rehabilitations.

In addition, the authors have been unable to identify any studies that have evaluated the loads on the bone/ implant interface during the removal of these prostheses, such as during their cleaning. O-ring and bar-clip systems stabilize prostheses with a force that is transmitted to bone surrounding the implant. ${ }^{14-18}$ The correct cleaning procedure is important for maintaining oral health and to guarantee the longevity of prosthetic rehabilitations, decreasing the risk of stomatitis. ${ }^{19}$

Photoelastic and strain gauge analyses are suitable methods for biomechanical evaluations. Photoelasticity is based on the phenomenon of polarized light passage, resulting in the formation of colorful patterns known as isochromatic fringes when loads are applied. These fringes can confirm whether the stress patterns can result in failures of a laboratory model. ${ }^{20}$ Strain gauge analysis is based on electrical resistance applied in vivo and in vitro under static or dynamic loads ${ }^{14}$ to evaluate elastic deformation. Some authors ${ }^{21-23}$ have used both photoelastic and strain gauge analysis to evaluate tensions around the prosthesis/implant/bone assembly.

The purpose of this in vitro study was to evaluate different attachment systems used with implant-retained obturators at dissipation loads under shear forces by using photoelasticity and strain gauge methods to simulate removal by the patient. The null hypothesis was that no difference would be found in stress under shear between the attachment systems.

\section{MATERIAL AND METHODS}

An experimental maxillary model was made with an oralsinus-nasal communication using Type IV dental stone (Durone; Dentsply Sirona). Using a parallelometer, dental implant analogs $(4 \times 13 \mathrm{~mm}$, TitamaxTi; Neodent $)$ were fixed at the incisor, canine, and first molar regions of the stone model. Impression transfer copings (Squared transfer 4.0; Neodent) were screwed to the analogs and fixed using dental floss and acrylic resin (DuraLay; Reliance Dental Mfg Co). Silicone polymer (liquid silicone;

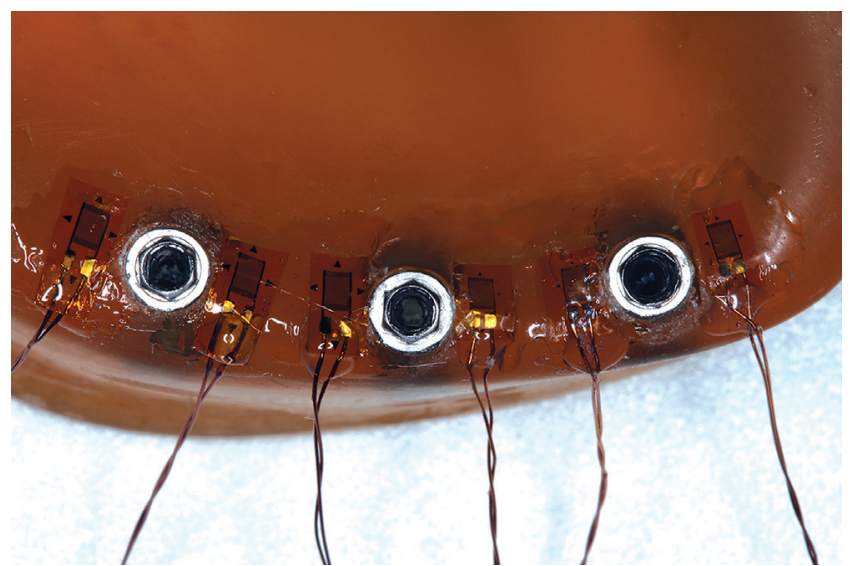

Figure 1. Strain gauges placed horizontally at mesial and distal sides of implants on marginal ridge of photoelastic model.

Sapeca Artesanato) was used to obtain an impression of the model with the analogs (analogs 4.0; Neodent) in place. The external hexagon implants were screwed into the obtained mold.

To obtain the photoelastic molds, PL-2 photoelastic resin (PL-2 resin; Vishay Precision Group, Inc) was manipulated according to the manufacturer's instructions and inserted into the silicone mold with the implants. After its polymerization under $280 \mathrm{kPa}$, it was separated from the mold and polished with fine grit abrasive paper (\#400, \#600, \#1200 - CarbiMet 2; Buehler).

Two obturators of clear autopolymerizing acrylic resin were made from the experimental stone model (Vipi Flash; Vipi Produtos Odontológicos). Three metal hooks ( 1 at the incisor and 2 at the first molar regions), which were used for different displacements, were placed.

For photoelasticity, the assembly (prosthesis/PL-2 model with O-ring or bar-clip system) was placed in mineral oil to minimize the refraction of white light and viewed with a circular polariscope. The prosthesis was displaced in the anterior, posterior, and vertical directions with a universal testing machine (EMIC DL-3000) at a constant speed of $50 \mathrm{~mm} / \mathrm{min}^{14}$ until completely removed. This simulated the daily removal of the prosthesis by the patient. The fringe patterns were recorded through a specialized filter connected to a digital camera (Canon Rebel T3i; Canon Inc) and transferred to a computer for qualitative analysis using imaging software (Adobe Photoshop CS6; Adobe Systems). The same trained examiner quantified the results by counting the high-intensity fringes (green to pink transition).

After this analysis, 2 strain gauges were placed horizontally at the mesial and distal sides of the implants on the marginal ridge of the photoelastic model (Fig. 1). Each strain gauge was configured into a one-quarter Wheatstone bridge and its data were transferred through a data acquisition system (ASD 2000; Lynx Tecnologia Eletrônica Ltda). The same displacements for 

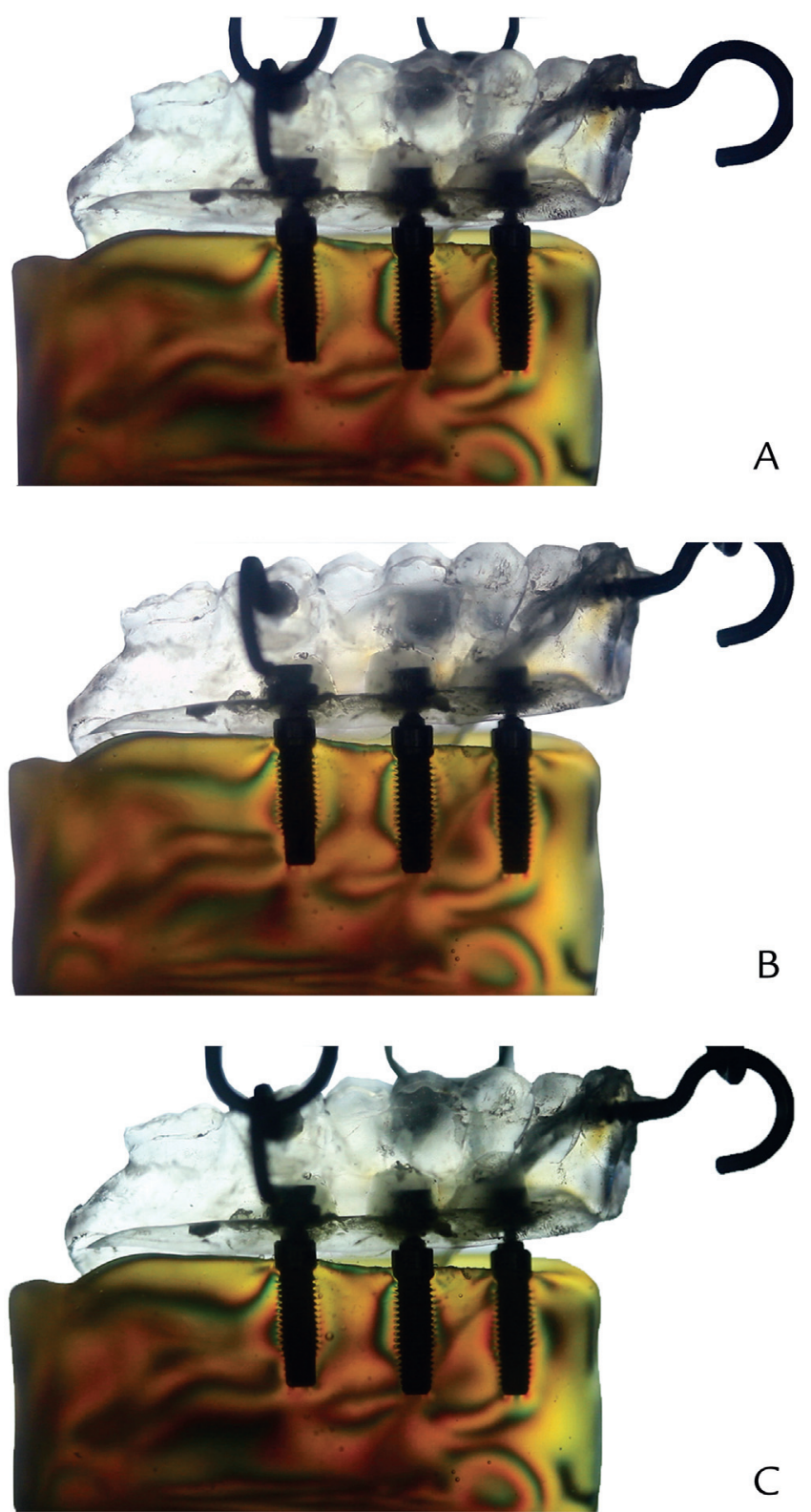

Figure 2. Shear force with O-rings. A, Posterior. B, Anterior. C, Vertical.

photoelasticity were repeated in the strain gauge test. Each displacement was performed 5 times for each specimen of attachment system ( $\mathrm{O}$-ring $\mathrm{n}=5$; bar-clip $n=5$ ), and the average for each displacement was calculated. After obtaining the average values from the vertical, posterior, and anterior displacement of the specimen, it was replaced by the next specimen.

The averages of the strains recorded in microstrains were grouped in tables and submitted to statistical analysis with a 2 -way ANOVA ( $\alpha=.05)$.

\section{RESULTS}

Results were based on the stress pattern images of the PL-2 models according to the order of the fringes after
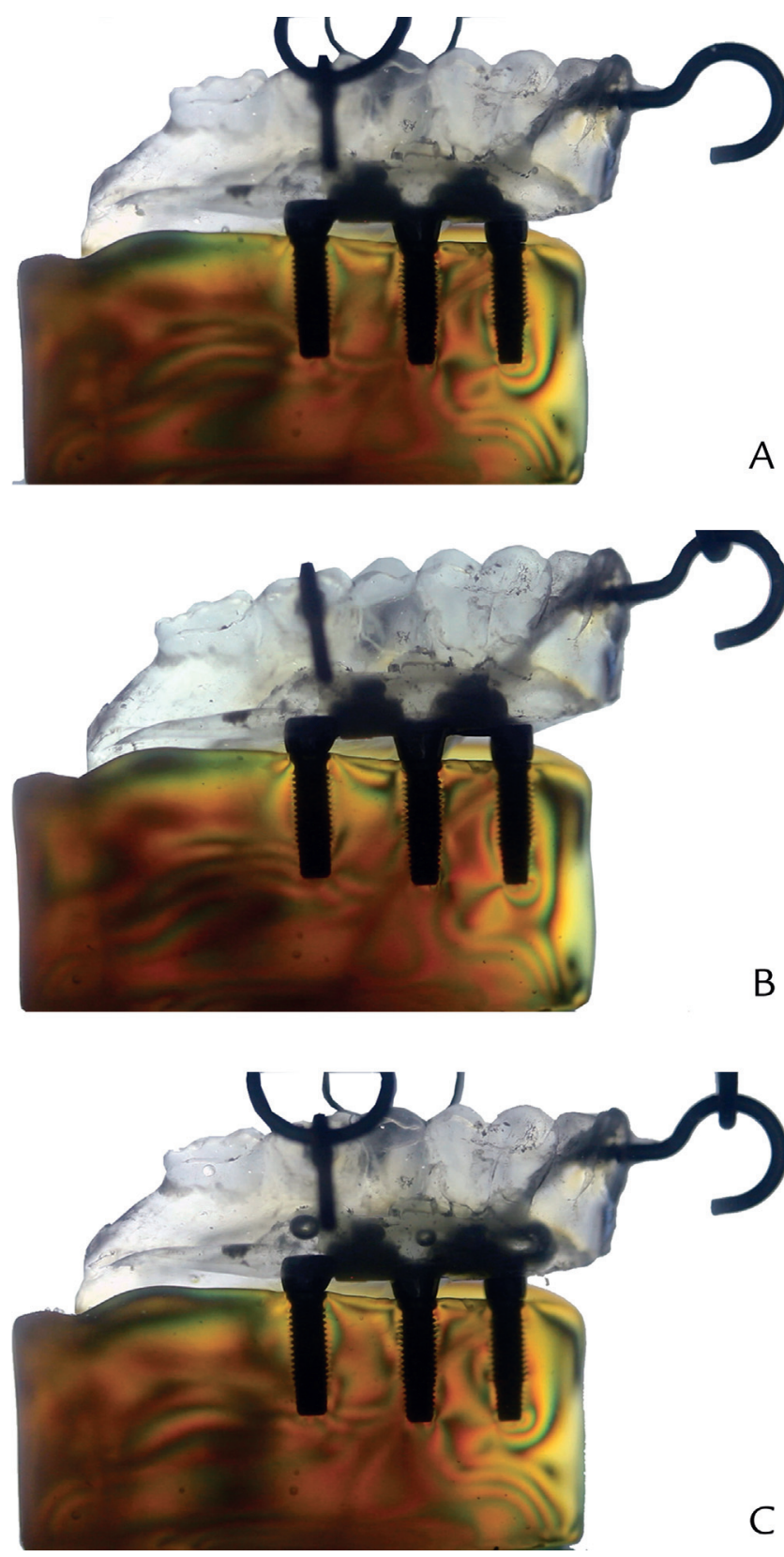

Figure 3. Shear force with bar-clips. A, Posterior. B, Anterior. C, Vertical.

the loads by using the photoelastic method. A low number of high-intensity fringes were observed during prosthesis removal. There were no high-intensity fringes in the O-ring group (Fig. 2, Table 1).

Three high-intensity fringes (Fig. 3, Table 1) were observed in the bar-clip group, indicating a greater transfer of stress to the resin and consequently to the implant/bone interface. The high-intensity fringes appeared around the apex of the implant, related to shear forces.

From the strain gauge readings, the average values of the measured strains for each attachment system type (Tables 2, 3) showed that bar-clips had the lower values 
Table 1. Number of high-intensity fringes according to each system and displacement

\begin{tabular}{lcccc}
\hline & \multicolumn{4}{c}{ Displacements } \\
\cline { 2 - 5 } Attachment System & Vertical & Anterior & Posterior & Total \\
\hline Bar-clip & 1 & 0 & 2 & 3 \\
\hline O-ring & 0 & 0 & 0 & 0 \\
\hline
\end{tabular}

Table 3. Average values (microstrains), standard deviation, and statistical analysis (2-way ANOVA) at 5\% significance level for O-ring and bar-clip systems, regardless of displacement type

\begin{tabular}{lcc}
\hline Attachment System & Mean \pm SD & $\boldsymbol{P}$ \\
\hline O-ring & $33.70 \pm 9.49$ & .007 \\
\hline Bar-clip & $23.04 \pm 10.57$ & \\
\hline
\end{tabular}

$P<.05$ denotes statistically significant difference.

of statistically significant tensions $(P=.007)$, regardless of displacement type. The comparison of each displacement, independent of attachment system, showed no statistically significant difference between the average values of the measured strains $(P=.518)$ (Tables 2,4$)$.

Table 5 lists the average values and standard deviation for the tested groups. No statistical difference was observed in the interaction of the displacement and attachment systems (Table 2).

\section{DISCUSSION}

The null hypothesis was rejected because a statistically significant difference was found in the shear forces between the attachment systems. Obturator prostheses are the most frequently applied treatment to rehabilitate patients after a maxillectomy. ${ }^{1,2}$ Loss of support, retention, and stability are common problems with conventional obturators. ${ }^{20}$ Implants and overdentures with attachment systems provide better retention, support, and stability in this type of rehabilitation. $2,7,8$

However, there is no consensus about the best retention system, considering the dissipation of loads from implants to the surrounding bone. In addition, few studies have analyzed tensile force during shear forces, which simulates prosthesis removal. ${ }^{14}$

Thus, this study analyzed the stress in prostheses of implant-retained obturators during simulated removal movements. The photoelastic analysis showed the absence of high-intensity fringes in the $\mathrm{O}$-ring group and a few high-intensity fringes around the apex of the implant with the bar-clip system. With the photoelastic method, despite the fewer number of high- intensity fringes in the O-ring system, the differences were small.

When considering the strain gauge analysis, the barclip system showed statistically significantly lower tension values. The difference between the results of the 2 methods may be due to the location of the strain gauges (cervical, mesial, and distal regions of each implant) and
Table 2. Results of 2-way ANOVA

\begin{tabular}{lccccc}
\hline Source & SS & df & MS & F & $\boldsymbol{P}$ \\
\hline Attachment system & 851.40 & 1 & 851.840 & 8.709 & .007 \\
\hline Displacement & 132.099 & 2 & 66.050 & 0.675 & .518 \\
\hline Attachment system $\times$ displacement & 346.447 & 2 & 173.224 & 1.771 & .192 \\
\hline Error & 2347.509 & 24 & 97.813 & & \\
\hline Total & 27830.264 & 30 & & & \\
\hline
\end{tabular}

$P<.05$ denotes statistically significant difference.

Table 4. Average values (microstrains), standard deviation, and statistical analysis (2-way ANOVA) at 5\% significance level for displacement results, regardless of attachment system type

\begin{tabular}{lcc}
\hline Displacement & Mean \pm SD & $\boldsymbol{P}$ \\
\hline Vertical & $29.49 \pm 8.17$ & .518 \\
\hline Anterior & $25.43 \pm 10.3$ & \\
\hline Posterior & $30.19 \pm 14.86$ & \\
\hline$P<.05$ denotes statistically significant difference.
\end{tabular}

Table 5. Average values (microstrains) \pm standard deviation of tested groups

\begin{tabular}{lccc}
\hline & \multicolumn{3}{c}{ Displacement } \\
\cline { 2 - 4 } Attachment System & Vertical & Anterior & Posterior \\
\hline O-ring & $30.28 \pm 3.09$ & $31.65 \pm 7.48$ & $39.16 \pm 13.87$ \\
\hline Bar-clip & $29.70 \pm 11.79$ & $19.20 \pm 9.26$ & $21.22 \pm 10.57$ \\
\hline
\end{tabular}

the region where high-intensity fringes were observed (apex region of each implant).

Evaluating both methods, the bar-clip system performed better than the O-ring system, in that strains around implants are more damaging to marginal bone than to the apex of the implant. However, only 1 study could be found that evaluated the shear forces on implant-retained overdentures. ${ }^{14}$ These authors concluded that bar-clips had higher tension values on surrounding bone than O-ring or magnet systems. The difference in results seen in the study by Takeshita et $\mathrm{al}^{14}$ and this study may be due to different attachment systems being tested in each study.

The majority of studies evaluated strain during the application of compressive loads and mastication. The removal displacements described in this study resulted in conflicting findings. Comparing our results with previous studies, there is a lack of consensus as to the best attachment system to use.

Pesqueira et $\mathrm{al}^{1}$ found the best results with O-rings in implant-retained obturators submitted to compressive occlusal forces. Machado et $\mathrm{al}^{11}$ used the photoelastic method to compare O-ring, bar-clip, and bar-clip with $\mathrm{O}$-ring systems in cantilever under compressive loads. That study observed that O-rings showed lower values of tension, followed by bar-clips, and bar-clips with O-rings in cantilever. Corroborating these results, Chun et $\mathrm{al}_{1}^{15}$ with finite element analysis, and Manju and Sreelal, ${ }^{9}$ with strain gauge analysis, found lower stress values for O-ring systems than bar-clips. This 
improved distribution of stress when dentures are submitted to compressive loads might be explained by the rubber O-ring in the female component absorbing strains. ${ }^{15}$

However, some studies ${ }^{12,16}$ reported lower strain values on bar-clips than O-rings submitted to compressive occlusal loads. Vafaei et $\mathrm{al}^{12}$ suggested that bar-clips possess a more favorable design to distribute the loads than O-rings. The design of the bar-clip system should be considered. Rismanchian et $\mathrm{al}^{17}$ reported that the height of the metal bar interfered with the strains generated around implants and surrounding bone, the 0 -mm height (bar touching the gingival tissue) presented the higher values of tension on bone tissue, and the ones with 1 - or 2 -mm height showed less stress. ${ }^{20}$ In addition to the height, the bar settings should be considered because, according to Prakash et al, $^{18}$ the bar settings interfere with stress distribution.

The present in vitro study has limitations, in that it did not completely replicate the oral cavity. A third method, namely 3-dimensional finite element analysis, might help clarify the results, and clinical evaluations are necessary.

\section{CONCLUSIONS}

Based on the results, and considering the limitations of the present study, it was concluded that the bar-clip attachment system had a better biomechanical performance with the lowest strain values around the dental implants and few high-intensity fringes around the apex of the implants when subjected to forces simulating prosthesis removal.

\section{REFERENCES}

1. Pesqueira AA, Goiato MC, dos Santos DM, Haddad MF, Andreotti AM, Moreno A. Stress analysis in oral obturator prostheses: imaging photoelastic. J Biomed Opt 2013;18:061203.

2. Goiato MC, Ribeiro Pdo P, Pellizzer EP, Pesqueira AA, Haddad MF, dos Santos DM, et al. Photoelastic analysis to compare implant-retained and conventional obturator dentures. J Biomed Opt 2012;17:061203.

3. Keyf F. Obturator prostheses for hemimaxillectomy patients. J Oral Rehabil 2001;28:821-9.

4. Goiato MC, dos Santos DM, Moreno A, Santiago JF Jr, Haddad MF, Pesqueira AA, et al. Prosthetic treatments for patients with oronasal communication. J Craniofac Surg 2011;22:1445-7.

5. Singh M, Bhushan A, Kumar N, Chand S. Obturator prosthesis for hemimaxillectomy patients. Natl J Maxillofac Surg 2013:4:117-20.

6. Kim DR, Lim YJ, Kim MJ, Kwon HB. The importance of remaining teeth reconstruction in the definite obturator for a hemimaxillectomy patient. J Craniofac Surg 2011;22:2359-61.
7. Kreissl ME, Heydecke G, Metzger MC, Schoen R. Zygoma implantsupported prosthetic rehabilitation after partial maxillectomy using surgical navigation: a clinical report. J Prosthet Dent 2007;97:121-8.

8. Nguyen CT, Driscoll CF, Coletti DP. Reconstruction of a maxillectomy patient with an osteocutaneous flap and implant-retained fixed dental prosthesis: a clinical report. J Prosthet Dent 2011;105:292-5.

9. Manju V, Sreelal T. Mandibular implant-supported overdenture: an in vitro comparison of ball, bar, and magnetic attachments. J Oral Implantol 2013;39: 302-7.

10. Porter JA Jr, Petropoulos VC, Brunski JB. Comparison of load distribution for implant overdenture attachments. Int J Oral Maxillofac Implants 2002;17: 651-62.

11. Machado AC, Cardoso L, Brandt WC, Henriques GE, de Arruda Nobilo MA. Photoelastic analysis of the distribution of stress in different systems of overdentures on osseous-integrated implants. J Craniofac Surg 2011;22. 2332-6.

12. Vafaei F, Khoshhal M, Bayat-Movahed S, Ahangary AH, Firooz F, Izady A et al. Comparative stress distribution of implant-retained mandibular ballsupported and bar-supported overlay dentures: a finite element analysis. J Oral Implantol 2011;37:421-9.

13. Cekic C, Akca K, Cehreli MC. Effects of attachment design on strains around implants supporting overdentures. Quintessence Int 2007;38: e291-7.

14. Takeshita S, Kanazawa M, Minakuchi S. Stress analysis of mandibular twoimplant overdenture with different attachment systems. Dent Mater J 2011;30:928-34.

15. Chun HJ, Park DN, Han CH, Heo SJ, Heo MS, Koak JY. Stress distributions in maxillary bone surrounding overdenture implants with different overdenture attachments. J Oral Rehabil 2005:32:193-205.

16. Fanuscu MI, Caputo AA. Influence of attachment systems on load transfer of an implant-assisted maxillary overdenture. J Prosthodont 2004; 13:214-20.

17. Rismanchian M, Dakhilalian M, Bajoghli F, Ghasemi E, Sadr-Eshkevari P. Implant-retained mandibular bar-supported overlay dentures: a finite element stress analysis of four different bar heights. J Oral Implantol 2012;38: 133-9.

18. Prakash V, D'Souza M, Adhikari R. A comparison of stress distribution and flexion among various designs of bar attachments for implant overdentures: a three dimensional finite element analysis. Indian J Dent Res 2009;20:31-6.

19. Peracini A, Andrade IM, Paranhos Hde F, Silva $\mathrm{CH}$, de Souza RF. Behaviors and hygiene habits of complete denture wearers. Braz Dent J 2010;21:247-52

20. Ochiai KT, Williams BH, Hojo S, Nishimura R, Caputo AA. Photoelastic analysis of the effect of palatal support on various implant-supported over denture designs. J Prosthet Dent 2004;91:421-7.

21. Cehreli M, Duyck J, De Cooman M, Puers R, Naert I. Implant design and interface force transfer. A photoelastic and strain-gauge analysis. Clin Oral Implants Res 2004;15:249-57.

22. Akca K, Cehreli MC. A photoelastic and strain-gauge analysis of interface force transmission of internal-cone implants. Int J Periodontics Restorative Dent 2008;28:391-9.

23. Cehreli MC, Akca K. Narrow-diameter implants as terminal support for occlusal three-unit FPDs: a biomechanical analysis. Int J Periodontics Restorative Dent 2004;24:513-9.

\section{Corresponding author:}

Dr Marcelo Coelho Goiato

Aracatuba Dental School

Department of Dental Materials and Prosthodontics

José Bonifácio, 1193 - Vila Mendonça 16015-050

Aracatuba, São Paulo

BRAZIL

Email: goiato@foa.unesp.br

Copyright () 2016 by the Editorial Council for The Journal of Prosthetic Dentistry. 